\title{
Designing successful post-retirement solutions by blending growth, income and protection
}

\section{Abstract of the Edinburgh Discussion}

[Institute and Faculty of Actuaries, Sessional Research Event, Edinburgh, 23 May 2016]

This abstract relates to the following paper: Morgan, L-A. and Lothian, S.A. Designing successful post-retirement solutions by blending growth, income and protection. British Actuarial Journal, doi: $10.1017 /$ S1357321717000034

The Chairman (Mr A. H. Watson, F.F.A.): As an introduction to the authors, we have Scott Lothian, who works for Baillie Gifford and is an investment manager in the Multi-Asset Team. Prior to this, he worked for Schroders in London, BAE Union in Hong Kong and Towers Watson in both London and Hong Kong. He has a degree in actuarial maths from Heriot-Watt University, and is a Fellow of the Institute and Faculty of Actuaries (IFoA).

Lesley-Ann Morgan, of Schroders, is Global Head of Defined Contribution (DC) at Schroders. In this role, she is responsible for setting the DC strategy for the firm and is a regular speaker at conferences on DC (pre- and post-retirement). Lesley-Ann previously worked at Towers Watson in the UK and New York. She too is a Fellow of the IFoA.

Miss Miss L-A. Morgan, F.I.A. (introducing the paper): Scott (Lothian) and I realised when we were working with many different DC plans around the world that there seems to be no one answer to post-retirement. When we thought about it, we felt that the risks and the issues that people were having to deal with in different countries were the same from country to country, but we could not understand why there were so many different solutions, and why there did not seem to be one.

So, that got us started on some more in-depth work into what happens in other markets and to try and obtain some lessons that we could learn. This gave us a better understanding of the problem which is now in many markets and is a ticking timebomb in a number of others.

The idea of retirement is obviously a relatively new concept. For most part of human history, people worked for as long as they could and then they stopped work and dropped down dead. So the fact that people were not living that long did not really matter. Initially Defined Benefit (DB) schemes were affordable. When the expected lifetime is 68 years and you finish work at 65 , then that is clearly very affordable.

But what happens in DC is that when the risks are passed to individuals, the risks become enormous for each individual to bear. Most of the actuarial concepts that we know work well when you share risk among many different people, though all over multiple time periods. But when you are an individual in a DC plan, the idiosyncratic risk is very high. Basically, each individual DC retiree just has one shot at it. 


\section{What are the risks individuals face in retirement?}
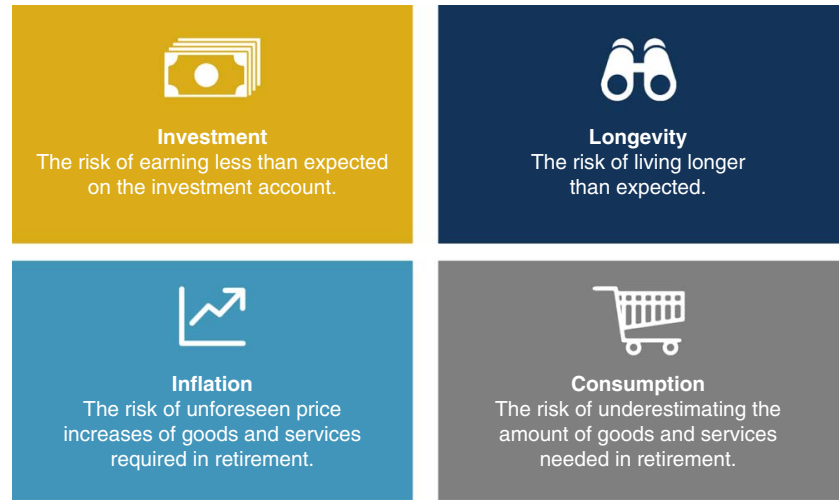

Source: Schroders, for illustration only.

Figure 1. What are the risks individuals face in retirement?

So, not being people who are daunted by the fact that there did not really seem to be one answer round the world, we embarked on trying to solve this problem using actuarial tools: investment strategy; insurance coverage; and financial advice. We were trying to come up with a perfect postretirement solution when we started this piece of work.

We went back to actuarial first principles to try to think about what were the risks for individuals facing retirement. Before I proceed onto the four risks in Figure 1, the biggest risk is insufficiency. The biggest determinant of this is whether people have saved enough during their working lives.

We are going to assume that a reasonable amount has been saved. Scott will cover what we mean by "reasonable" later on.

On the other side of the equation, insufficiency also relates to over-consuming or outliving your bank account. Whatever is the trigger, the real world outcome is the same. You have run out of money at a time in your life when you cannot really earn any more. With that in mind, let us look at the four risks in Figure 1 that help us shape what should be the post-retirement solution.

When we think about investment risk, we think about the risk of investment returns falling short of expectations, so in DC this includes sequencing risk; heavy losses that occur early in retirement when the account size is at its largest. We also include here high fees risk, taxation risk and the risk of receiving poor, expensive or biased advice within this particular area.

The next one is longevity. Obviously, many of you here know a lot about longevity risk; living longer than expected. Medical developments have resulted in people living longer and longer. That obviously causes a problem when we are trying to design post-retirement solutions.

There is also a subtle point within longevity. It relates to perception. Not everybody who buys a product, or is in a product in post-retirement, in DC understands that there are no guarantees in that product. Many people believe that when they have a DC plan, they will just be able to have an income which will last for life. There is a perception issue about longevity for most people. 
Moving on to inflation, when we think about inflation, we think about two types of inflation. We think about the slow, grinding type but also the sudden spiky type. The types of inflation that we are thinking about in post-retirement relate to the things that people buy in post-retirement.

When you do studies and look around the world about what people buy in post-retirement, it is not that sexy. It is housing, transport, food and, in some countries, it is medical, where they have to pay out of their pocket. All of those things are either part of the inflation index or rise higher than the standard inflation index. We need to be very cognisant of inflation.

We also have to remember that there are behavioural biases which mean people choose not to buy products that have inflation linking or protection within them. That is because most people underestimate inflation, or the impact of inflation, over long periods of time.

The final risk in Figure 1 is consumption. That is a risk of needing to spend more each year than you expect to spend. There is quite a lack of knowledge, I think, in the UK particularly about the costs of goods and services once you reach retirement.

There is also a risk within consumption that relates to lack of flexibility. If people need some money urgently and they are in some sort of product which has locked them in and they cannot get out of it, that causes a problem for them in post-retirement.

Those are the four main risks that people face in retirement. As investment actuaries in non-actuarial firms, Scott and I generally do not spend that much time thinking about designing an investment product based around actuarial methods.

What I have been really concerned about was the fact that I had not seen any work anywhere that showed which of these risks is the most dominant and how do these risks change over time? If we understood how those risks changed over time that would help us to be able to determine or design an appropriate product for people in post-retirement.

Mr S. A. Lothian, F.I.A.: We wanted to find a way to think about these different risks. What we then looked at was the sensitivity of the value of a pension to changes in the different risks. We put them together and show how those evolve over time.

What we looked at was the sensitivity of the simple present value calculation of the pension stream going out in future and to very small changes in each of these key assumptions. We are going to talk about consumption later. Consumption is really best dealt with by communication, education and, frankly, thrift.

We then looked at the other three types of risks in Figure 2. For investment, you would expect a larger risk at the start. When you have a large pot of money at the start of retirement, that is the point that you are most vulnerable to large market crashes, and also you have a long time ahead of you over which you need to gain the investment returns. This is a multiplier type of effect.

On the inflation side, there are similar arguments. You are looking across quite a long period of time. Somebody retiring today at age 65 can reasonably expect to live for another 17-20 years or so. You have that slow, grinding impact of inflation, sudden spiky types of inflation, and also you have 


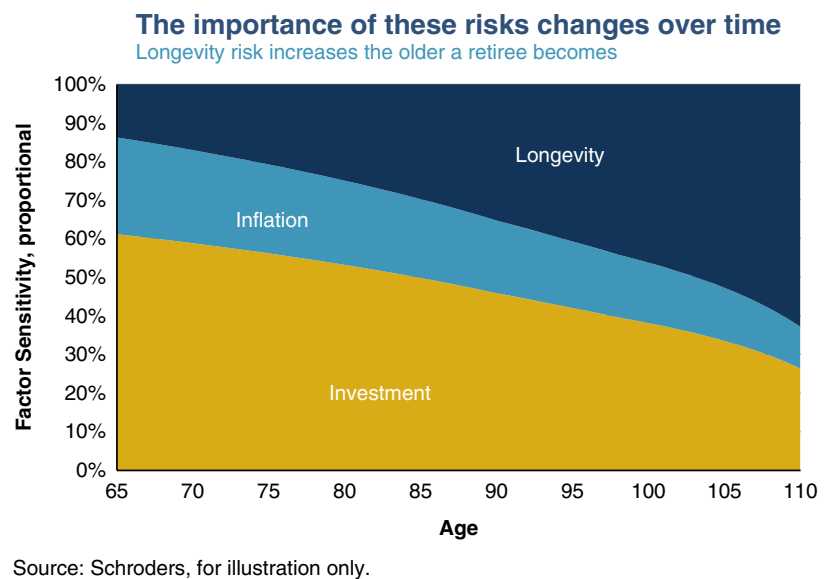

Figure 2. The importance of these risks changes over time

the types of goods and services that people will buy in retirement. These goods and services tend to experience higher inflation than the core headline inflation.

This is an exposure effect. Again, you can see in Figure 2, it declining over time. As it declines, it is replaced by that longevity risk.

Longevity, as I am sure many people are very well aware, is a self-fulfilling thing. The probability of an 89 -year-old making it to age 90 is a lot higher than the probability of a 65 -year-old making it to age 90 . The proportional increases with each additional year of life become bigger and bigger. With each additional year of life you would expect the total lifetime grows, but not by a full year. That is why the proportional effect increases over time.

What do we take from this in our thinking? In the early days, early in retirement, it has to be about generating good, real returns to combat that investment risk and that inflation risk, and then towards the end, as you get later into retirement, it is more about making sure that it lasts.

We found that there are really three key building blocks that are used in all different markets that have a big DC element. These are common and are our starting points.

Let us start off with a cash lump sum with no conditions for use. This is pretty easy to understand. It is very popular. People like to have cash in hand. It is also, as we are going to come on to see, really risky. People often talk about the Lamborghini risk, or going on a world cruise. Possibly there are worse things people can do. Like just putting the money in the bank. In places like Hong Kong, this is what they do. Potentially, under Pensions Freedom, this is an option here in the UK as well.

Secondly, we have individual accounts. Some kind of account-based draw-down system. Perhaps there are rules enforced to say "These are the types of areas that you can invest in. These are the maximum amounts that you can draw down". This is the well-used approach in places like South Africa and Chile. You have some rules but you also have flexibility for individuals. It is in keeping with a move from DB to DC; the flexibility, the risk, remains with the individual. 
Finally, we have annuities or other different types of longevity risk sharing. As I am sure many of us know, this is a way where many different individuals can come together, whether by virtue of an insurance setup or other types of pooling, to guarantee themselves an income for life, bringing in that element and maybe ceding some of that risk from the individual back to the insurance company or the mortality pool, whatever that might be.

As I mentioned, Hong Kong is firmly in the lump sum area. You reach retirement age in Hong Kong. You have saved in your mandatory provident fund section and a cheque is given across. There are no strings about what you can do with this. Quite often it goes into the property market, the local stocks and shares market or under the mattress.

Just a short hop from there in Singapore, a rather more draconian situation. You have a governmentsponsored annuity system. In this market you have compulsory annuity purchase, but at rates dictated by the government. Many of you may be familiar with Singapore. It has one of the highest saving rates in global DC, lots of compulsion for people to save, lots of support, a very paternalistic society.

A lot of this is driven by politics. You have this confluence of a large majority of the population and generally an older majority of the population (older people tend to vote more) so it is an important part of the population for many of our politicians, and fairly large sums of money are involved. So we have seen quite a lot of interference between short-term politics and this long-term problem of being able to provide enough throughout retirement.

That is also what we have seen in the UK and Australia over the past couple of years. Australia starts off with individual accounts/lump sums. They had the Murray Report and were very worried about spending the money on Lamborghinis or just putting it in the bank and running out of money later in retirement. So they moved more into annuitisation. At the same time, the UK moved in the other direction. The UK wanted to move away through Pension Freedom and so politics intervened here and has moved the UK more towards individual accounts, and greater access for people to cash lump sums.

The politically unpopular answer is to have people working for longer. That is an inevitability. Many people have reached retirement age, they realise that they have insufficient savings and will work longer and longer. That will have an impact on the amount that they can save and the amount of time that they will spend in retirement.

If we look across to the US, you have Clinton and Trump who are 68 and 69 years old respectively. They are past retirement age, but going for a new job which will last for a few years. But, of course, neither of them has come out and said that they will make retirement ages higher because they are already probably unpopular enough.

Bernie Sanders is 74 . He is in that same camp as well, although I think that he has come out and advocated a higher retirement age.

Lesley-Ann and I are investment actuaries. We thought we could try to solve this problem using all these whizzy investment products that we have within our respective organisations.

We started off by saying that we need to have a metric at which to look. I am going to give you a quick definition of the coverage ratio. The coverage ratio is the total sterling value, or dollar value, of an individual's account, divided by the most recent annual withdrawal. 


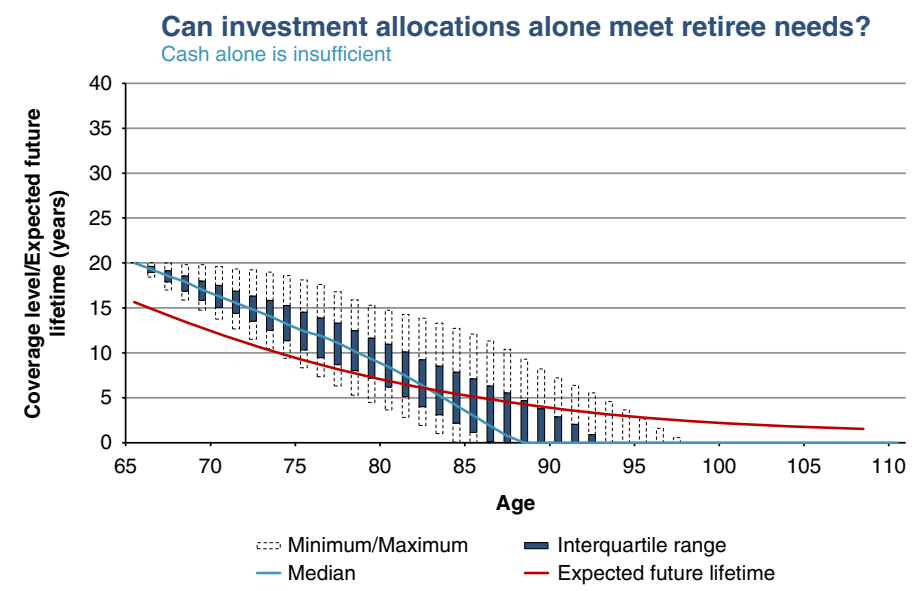

Source: Schroders, Thompson Datastream. For illustration only. For assumptions see appendix.

Figure 3. Cash alone is insufficient

You are going to have something that is denominated in pounds, and I am going to divide it by something that is denominated in pounds per year.

The resulting coverage level is basically how long, in years, you would expect your DC pot to last.

Let us consider an individual and assume that he has done a great job of saving throughout his career and he has saved to 12 times his final salary by the end. He wants to get a $60 \%$ replacement ratio, and so his starting coverage level will be 20 years. And let us assume that he puts his fund in the bank.

We looked at all the different bank saving rates over the course of the past 65 years and ran lots of scenarios over that period using the actual data to see how this would have panned out. We have a range of different outcomes, as shown in Figure 3.

This is how this coverage ratio moves over time. Figure 3 shows the minimum, maximum, the interquartile range and the median.

In the median situation, he runs out of money around age 87 . And remember that this is someone who has saved a great deal of money.

What we need to do is to compare that to this person's expected future lifetime. We want to try to bring longevity into it. At age 65, our individual, according to the actuarial tables, will have 16 or 17 years to live. The red line in Figure 3 shows how the expected future lifetime progresses with each further year survived. It does not fall by one each and every year because of that self-fulfilling longevity issue that we talked about before.

Where the median and the longevity line cross, we think of this as a tipping point. It is the point after which the odds of running out of money tip against the individual. Up until the lines cross, the balance of probabilities, based on past historic data, is that you will not run out of money. But once you get beyond that point, it is a problem and it continues to be so. 
Can investment allocations alone meet retiree needs?

Increasing risk improves median sufficiency but introduces tail risks
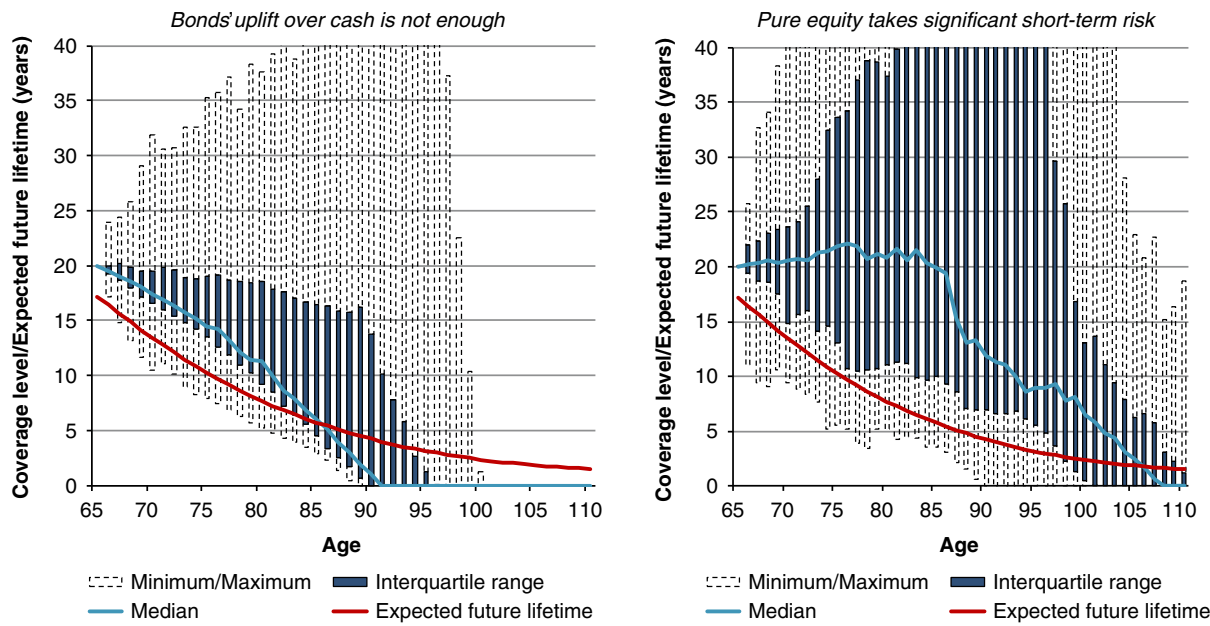

Source: Schroders, Thompson Datastream. For illustration only. For assumptions see appendix.

Figure 4. Increasing risk improves median sufficiency but introduces tail risks

That shows us that cash alone is sufficient up until about that tipping point but then there is absolutely no longevity protection whatsoever. If this individual survives a lot longer, there is nil protection in the portfolio.

In Figure 4 we have a look at fixed income and equity portfolios.

We are looking at the same kind of things. We are looking at the median coverage ratio, and we are comparing that to the expected future lifetime. We have managed to make the money last a little bit longer in the case of bonds. The tipping point is a little bit further across, but you still have a tail. What you also begin to see (particularly for the equity portfolio) is that there is this early stage issue, referred to as sequencing risk.

Equities look great as you have pushed the tipping point way out past this individual's 105 th birthday. However, the minimum returns in the early days take you way down past the longevity line. It is very difficult to stick with that same investment strategy if you have had that experience at the very start. That makes it very tricky and that is where investment psychology kicks in. Equities take too much short-term risk to be a comfortable investment strategy.

Figure 5 shows a 50-50 model. That is a good enough place to start. Here again, you still have the tipping point pushed out pretty far, but there is still a sequencing risk early on. There are many types of investment strategies out there, many of which are designed to meet this exact need.

While we can improve the metrics we are targeting, we can push that tipping point further out, we can try to make the investment pot last a little bit longer, it is still not always enough. So we still cannot really solve the longevity problem with an investment solution alone. 


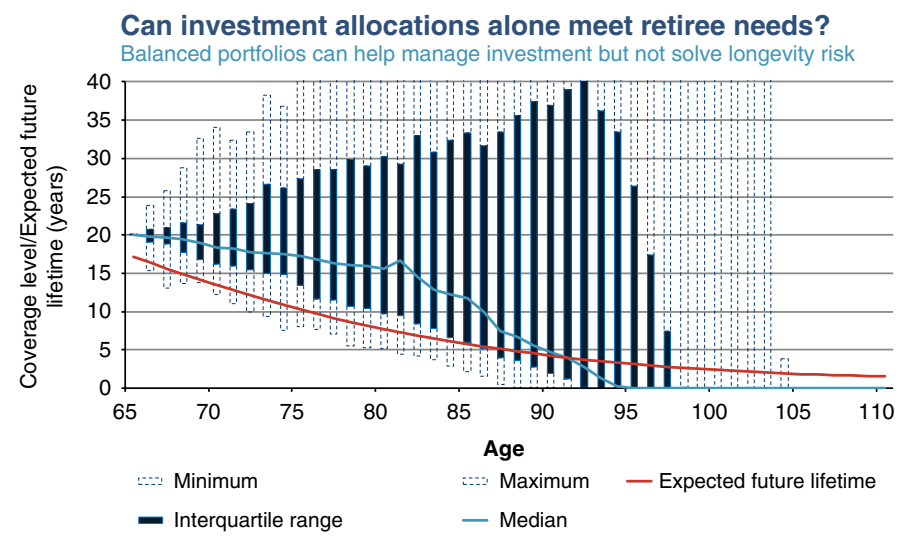

Source: Schroders, Thompson Datastream. For illustration only. For assumptions see appendix.

Figure 5. Balanced portfolios can help manage investment risk, but not solve longevity risk

We made this hugely bold assumption at the very start of somebody having saved 12 times their final salary, wanting a $60 \%$ replacement ratio. We all know that that is way in excess of what most people have in the UK, let alone in many other parts of the world, where the saving rates are way below the portfolio that we have here.

So that assumption was patently crazy and was for the purposes of illustration. If you think of somebody who has saved let us say five times final salary and is looking for a $50 \%$ replacement ratio, then the starting coverage level would be 10 . You had never even given yourself a chance of reaching that tipping point. You are past it before you have even started. So it comes back again to the point about sufficiency of savings and the issue of consumption.

Miss Morgan: At this point, this is where we have to put our commercial hats on because, as individuals working for asset managers, it is important to design something that not only meets the need, but people want to buy. As we have continued our research in this area, we realised that the risks that people face in retirement often have very little to do with the products that they buy. Or another way to think about this is that the needs and the wants are very different.

As we did our research, we realised that the wants did not really differ that much from country to country, and the needs did not differ that much from country to country. But the wants and the needs themselves were very different, much more in post-retirement than in any work we had done in pre-retirement.

Taking all the research into consideration, we have boiled this down to four needs and four wants. The needs are the answers to the three risks we talked about earlier on: stable returns; inflation protection; and longevity protection. I also include flexibility because, as we talked about, people do need to have some flexibility in their post-retirement answer.

When we come on to the wants, what we have is, firstly, adequacy. So will your income last? 
The next one is predictability. Understandably, people want to know how much they are going to have to live on each month, because if it fluctuates around, they find it quite hard to plan. One of two things may happen. If it fluctuates around in a negative way, people start to hoard, and this is some of the experience that has started to be seen in Australia. The other way is if people start to do really well with their investments, they start to over-spend or over-consume. So, predictability is quite important in a post-retirement designed product.

The next one relates to simplicity. As we know, financial literacy is pretty poor everywhere. By "poor" what we mean is really poor. There was some behavioural analysis that was done originally in the US by Lusardi and Mitchell. They basically had three questions for ascertaining whether or not people are financially literate.

The first question is: if you are given $\$ 100$ and the investment return is $2 \%$ per year, after 5 years will you have less than $\$ 102$, equal to $\$ 102$ or more than $\$ 102$ ?

The second question was: if the interest rate is $1 \%$ and inflation is $2 \%$, after 1 year will you be able to spend your money on less than what you had before, the same as what you had before or more than what you had before?

Question number three is: is it more risky to invest in a single company's stock or a stock mutual fund?

In America, only half those over the age of 50 could answer questions one and two correctly. Less than a third answered all three correctly.

Before you think that that is just Americans, they have done the study in many different countries and the results are very similar from country to country. So when I talk about simplicity here, we are talking about super-simple. People are struggling with these types of questions.

Finally, we have legacy benefits. As I said upfront, personal funding for retirement is a relatively new concept and is typically under-funded, as Scott said. The reality of funding for retirement but also funding for legacy, so to hand something on to your kids or your grandchildren, is something that the majority of people are not going to be able to afford.

When you look at studies into what people want their DC account to be able to do, they want to be able to hand something on after they die. This is one of the things that people assess when they think about how attractive a post-retirement product is.

We evaluated each of the three options that Scott talked about against the wants and the needs.

Referring to Figure 6, we split the stable return into growth and protection against significant loss. That is the $2 \mathrm{a}$ and the $2 \mathrm{~b}$. We have also split inflation protection into the slow one and the spiky one. That is $3 a$ and $3 b$.

If you take a step back, and see how many red traffic lights are against each one of these, you will see that cash lump sums and fixed annuities come out equally as bad as each other. Depending on whether or not you think longevity protection or flexibility is more important, will determine which of those two is the worst of the three. 
Testing the options against our criteria

Does anything offer everything a retiree needs? (Primary criteria)

\begin{tabular}{|c|c|c|c|c|c|c|}
\hline $\begin{array}{l}\text { Primary } \\
\text { Criteria }\end{array}$ & $\begin{array}{l}\text { 1. Longevity } \\
\text { protection }\end{array}$ & $\begin{array}{l}\text { 2a. Growth } \\
\text { net of fees }\end{array}$ & $\begin{array}{l}\text { 2b. Protect } \\
\text { against } \\
\text { significant } \\
\text { loss }\end{array}$ & $\begin{array}{c}\text { 3a.Inflation } \\
\text { protection } \\
\text { (increases in } \\
\text { costs) }\end{array}$ & $\begin{array}{c}\text { 3b.Inflation } \\
\text { protection } \\
\text { (inflation } \\
\text { spikes) }\end{array}$ & 4.Flexibility \\
\hline $\begin{array}{l}\text { Cash lump } \\
\text { sum }\end{array}$ & & & & & & \\
\hline $\begin{array}{l}\text { Individual } \\
\text { accounts }\end{array}$ & & & & & & \\
\hline $\begin{array}{l}\text { Fixed } \\
\text { annuities }\end{array}$ & & & & & & \\
\hline
\end{tabular}

Likely to satisfy

Unlikely to satisfy

Depends on product, investments and market environment

Source: Schroders

Figure 6. How do the typical components fare on our primary criteria?

We have picked fixed annuities here because that is what the vast majority of people selected prior to Pension Freedoms when they reached retirement. So it seemed like a reasonable thing to use as a comparator.

On Figure 7, you will see how the three options stack up against the wants. You will see that cash is king as it is easy to understand; people know what they are going to receive by way of a return - nothing or less than nothing at the moment; and it can be handed on when they die. It scores very well against the wants criteria. No wonder it is a challenge when we try to design something that is meeting both the wants and the needs.

Individual accounts are more complex. Again, the choice of underlying funds available in this particular category can be quite confusing.

Annuities are easy to understand and predictable, but they lack legacy benefits generally and this deters people in countries such as the US. In the US, annuities are not popular despite being available in postretirement because people not only feel that they are not flexible enough, but they also worry that insurers are not secure enough. They do not really understand enough about all the legislation and the regulation that goes behind insurers, so they worry about putting their entire account with one provider.

At this point was when Scott and I were beginning to realise that this is why there is not one answer around the world. We have people who mostly do not care or do not understand about investments and annuities, who in the main, in the UK, have never made a decision in pre-retirement because the vast majority of people are in a default position.

They reach retirement, they are faced with a lot of choice and they have little or no advice. They are at risk of being scammed and this is when their fiduciaries basically say "Goodbye. You are on your own now". It is a really big problem.

What we have suggested in the paper is that if fiduciaries are up for the challenge, they could retain members in the plan in post-retirement. Obviously, there are pros and cons. But, on balance, 
Testing the options against our criteria

Does anything offer everything a retiree wants? (Secondary criteria)

\begin{tabular}{|c|c|c|c|c|}
\hline Secondary criteria & $\begin{array}{l}\text { 1. Predictability } \\
\text { of income }\end{array}$ & 2. Legacy benefits & 3. Simplicity & 4. Sufficiency? \\
\hline \multicolumn{5}{|l|}{ Cash lump sum } \\
\hline \multicolumn{5}{|l|}{ Individual accounts } \\
\hline Fixed Annuities & & & & \\
\hline Likely to satisfy & fy & tments & ket environment & \\
\hline
\end{tabular}

Figure 7. A different story on the secondary criteria

\section{Helping retirees select a suitable solution Providing guidance and tools}

'Select one from list $A$ and one from list $B$.

Choose the proportion to allocate to each'

\begin{tabular}{|ll|}
\hline List $\mathbf{A}$ - investment component & List $\mathbf{B}$ - protection component \\
\hline $\begin{array}{l}\text { 1. Investment portfolio targeting inflation }+1-2 \% \\
\text { p.a. over the long term }\end{array}$ & 1. Immediate annuity \\
$\begin{array}{l}\text { 2. Investment portfolio targeting inflation }+3-4 \% \\
\text { p.a. over the long term }\end{array}$ & 2. Deferred annuity (commencing at age 85) \\
\hline
\end{tabular}

Source: Schroders, for illustration only.

Figure 8. Providing guidance and tools

I think it probably comes down on the positive side for members to stay in the plan because it is probably better from a pricing perspective and from an outcome perspective. Even if they do not stay in the plan, fiduciaries and advisers could use the kind of approach outlined in Figure 8 .

What we have suggested is that there is a short list of options from which retirees can choose both the appropriate investment part and the appropriate protection part.

In my view, this is where "Robo" advice can really become helpful to fill the advice gap that we have in the UK. If you can have technology that can illustrate the different combinations of options, almost with a slide bar, so you can see how much you should have in each one and how long your investments might last for, I think that could help to make individuals take very difficult decisions at retirement. 


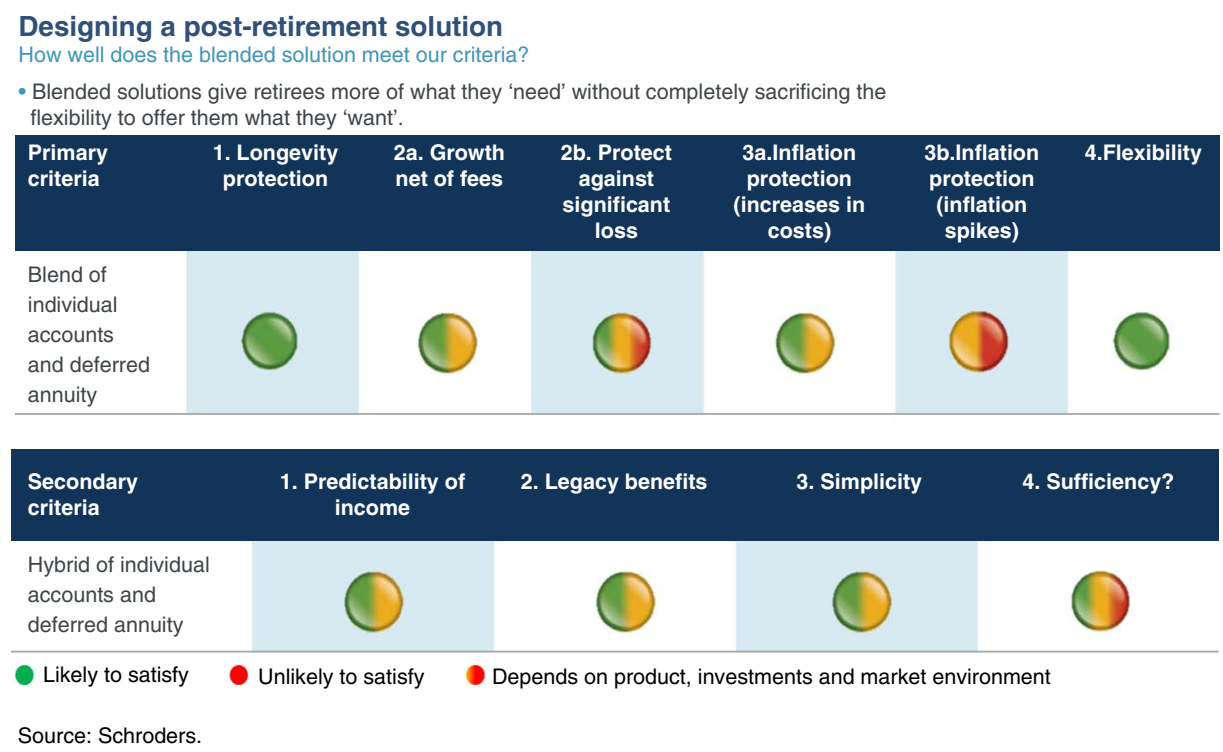

Figure 9. Blended solutions meet more of the needs of individuals in retirement

That brings us down, in the paper, to a hybrid or blended solution being the answer, possibly tailored for individuals with a better use of data about their existing assets and liabilities and their health.

Referring to Figure 9, is the combined entity better than its constituent parts? Well, it is not green across the board, but there are hints of green in almost every single one of these traffic lights. So, I would say that the hybrid solution is more preferable to the single component solution that we see in many countries around the world.

Just to sum up on our research and conclusions, the retirement account needs to be large enough or no solution is going to be sufficient in retirement. In most countries round the world, people are not saving enough, and even in those countries where they are, such as Singapore, to which Scott referred, the account is able to be used for other things. It is not just an asset to live off in retirement.

Once retirement is reached, individuals have to eke their money out over a longer and longer time period because life expectancy is increasing, but increases in retirement ages around the world are not generally keeping pace with that improvement.

In early retirement, we have advocated in this paper that individuals need risk-controlled growth based on the analysis that Scott showed you. In late retirement, they need some sort of longevity protection and, generally, individuals do need flexibility for accessing cash in an emergency.

The final design also needs to be simple for people to understand or they will not buy it.

Finally, as Scott discussed, retirement planning is a long-term gain. Having stability around the approach and the tax regime is imperative. People do not like to plan to save for 
retirement. They just like to think about what they are going to have to pay out in the next couple of years. If we have additional uncertainty around whether their savings might be further taxed or whether they might have limited access to those savings, it is likely to result in even less desire to save.

The Chairman: May I now invite John Taylor to open the discussion? John is head of guided outcomes delivery at Hymans Robertson. He started his working life as an actuary within the life insurance industry, and has spent most of his 20 years developing savings products and marketing them to customers.

He thought this was going to be a fascinating paper and now he is going to talk about it.

Mr J. Taylor, F.F.A. (opening the discussion): It is a little over 2 years ago now since George Osborne said to an astonished industry "Let me be clear, no one need buy an annuity". It seemed that we were being thrust into the unknown. However, as this welcome and circumspect paper explores in some detail, there is a wide area of practice internationally that can inform how we in the UK develop in this new market.

Other jurisdictions have their own ways of dealing with the same problem; that of helping savers to generate income throughout retirement when they have, in general, been under-saving and are expected to live longer.

The underlying challenge of producing a pattern of income in the face of investment and longevity risks is fundamentally an actuarial one.

Given the skills that actuaries have developed in helping institutions manage assets and liabilities, the authors reinforce that there is more that we as a profession can do to help individual consumers manage their own assets and liabilities in this era of individual responsibility.

In drawing lessons, the authors are mindful that cultural and taxation issues mean that there is not always a direct read across from one country to another. In particular, the authors are very mindful of the influence of politics. Indeed, the UK's pension policy has, in recent years, been shaped by the need to bolster tax revenues at a time of economic austerity.

I know that Scott has also examined the collective DC arrangements in the Netherlands, where there is a concern that pensions in payment are benefiting unfairly from smoothing up, at the expense of younger savers, because pensioners are such a powerful voting lobby.

These concerns have prompted many in the UK to advocate an independent pensions commission, and I wonder if the authors' international perspective can shed any light on that question.

Later in the paper, when hybrid solutions are considered, the authors are emphatic that some element of insurance is necessary to manage longevity risk. I recall one commentator saying, after George Osborne made his announcement, that we were in danger of throwing the cross-subsidy baby out with the market failure bathwater. A slightly contrived analogy and I will repeat it once more: we are in danger of throwing the cross-subsidy baby out with the market failure bathwater. 
This analysis clearly shows that any product solution that does not involve cross-subsidy leaves the consumer with a material risk of outliving the fund. With the current aversion to annuities, we need to consider carefully how we educate the UK consumer about these risks and how to manage them. This could be a fruitful area for further development.

Having a suite of products that meet the underlying needs is only half the battle. Consumers need to know when and how to use them. With low levels of financial literacy and lack of affordable advice, we need to give more consideration to communication at the point of product selection and on an ongoing basis.

One specific point that would benefit from further research is the use of post-retirement default. The authors argue against this in paragraph 6.4.4. of the paper. I have observed that an accumulation default has been a cornerstone in the UK's successful auto-enrolment policy. Providing a default does not preclude offering alternatives.

Health is a further area that would benefit from exploration. It is certainly touched on in the paper, given the potential need to fund long-term care fees, but the relationship between retirement finances and health is deeper. For example, the first resort for many who are approaching retirement under-saved will be to extend their working lives. Potentially, there could be an insurance solution for those who would choose to do that but are unable to do so because of health reasons. Of course, there is a very direct link between state of health and the rate achievable with underwritten annuities. As such, it is the biological age that is more important to retirement planning than the chronological age.

On a more technical front, I think the authors would have benefited from sharing their assumptions more explicitly in a couple of areas. For example, the analysis of hybrid solutions in section 6.2 is dependent on pricing assumptions for instruments, deferred annuities and later life annuities that are rarely available in the market. Similarly, an explanation of the methodology behind the interesting graph that Scott shared with us in Figure 2, showing the development of relative risks throughout retirement, would also have been helpful.

Finally, in pursuit of the perfect product, one that meets all the needs and wants, I think that we have to acknowledge that it is simply not possible.

Some of the criteria conflict with one another, most obviously achieving strong returns and providing downside protection: those two are in tension.

Less obviously, providing longevity insurance and offering flexibility. They too are in tension because of the need to constrain the product to mitigate against adverse selection, most notably deathbed transfers or surrenders.

Overall, however, this paper provides a valuable perspective as each country wrestles with solving the same problem in their own unique context.

Mr H. R. D. Taylor, F.F.A.: I think that this type of paper is probably overdue from the profession given what is happening in the market.

It is a good paper because it highlights the issues and the options in plain English and with no formulae and also states a preference, which is always good for stimulating discussion and debate. 
The preference is an account-based income and deferred annuity. I think in this whole area, there is huge scope for innovation, especially for the mass DC market, which has traditionally been less advised. I think the top end consumers will always be advised. Pension Freedoms have just opened up. There is even more choice.

The big issue is the mass-market UK plc. I think that many of these investors are currently in the accumulation phase and are currently in default funds. That is the kind of customer where the greatest potential for customer detriment emerges and that is where, in my view, the profession should focus its attention.

When I say that there is huge scope for innovation, it is innovation in its broadest sense, not just simply the kind of investment and insurance solutions that are possible, but also the mechanisms which are available to share risk and provide the insurance element. We should be thinking beyond just insurance companies, particularly because of the capital constraints imposed by Solvency II on deferred annuities. There are trusts, there are master trusts, there are mutuals and there may be other forms of vehicle which might be resurrected specifically to address the issue of how, in a modern environment, with these kinds of hybrid solutions, you can best provide mechanisms for the public to safely share risk amongst one another.

I will not mention the dreaded with-profits because I think that is something that has gone. Many of you who were in that era will recognise that there are elements of what with-profits used to do a long, long time ago that are relevant here.

When you look at each of the solutions, they look like pretty perfect solutions, and it is only in the text you see there is a fundamental flaw, such as in 6.2 .5 , the final sentence says: the median expiry age when we did the back testing is around aged 89 years.

I should like to have seen a line overlaid that shows what the back testing showed.

For the first solution, which is the preferred one, my thoughts are deferred annuities, yes, but there is no market for deferred annuities in the UK. Very few insurers offer them. I do not think that the pricing is particularly attractive and the capital requirements are just horrible. So I think that unless something changes, or unless some other non-insured route opens up, then we are going to be stuck with the lack of a viable, attractive market for deferred annuities.

For the second one, which is described in 6.2.6, I just wonder how around age 80, the process of the purchase of an annuity would happen. Would there be some kind of an auto-purchase at a specific age? Would that be with or without advice? How would all that work? Tying it into a particular age obviously imposes a significant investment timing risk, depending on interest rates and annuity pricing at the time. I think the practicalities of delivering that are perhaps more difficult than the paper suggests. Again, the backtest showing that only $82 \%$ of the target level would be achievable is one of the flaws.

Finally, for the third option, one of the issues of maintaining an increasing income is, of course, the higher the level of the annuity guarantee, the greater the gearing effect the pot has to produce. So, I wonder what kind of investment strategies might produce that kind of income because it is not a natural kind of cash flow that emerges from many investments.

Mr J. Hastings, F.F.A.: There is a remark that it all starts with having enough money when you retire. If you are going to encourage people into the accumulation phase, you need to provide them 
with some sort of idea that there are going to be solutions that provide for their pension as well, otherwise people do not trust what they are getting and then they just will not save at all.

In 6.4, the authors said that many people may be willing and able to choose their own path. This seems rather optimistic to me, given the level of poor financial literacy. If Andy Haldane, the chief economist of the Bank of England, admits he does not have a clue about pensions, then I wonder what chance many people will have.

It is not just about understanding. I think, even worse, it is a question of do they trust pensions at all? I think that is one of the issues that we need to overcome.

It is always nice to model, but I do wonder if even 60 years of data are enough. We could be in an era of secular stagnation with pretty weak investment returns for a long period to come.

I have recently seen more and more economists looking at something called UBI, which is universal basic income, as the replacement for a lot of means-tested benefits. I did wonder whether there was a way that that can be used to address individuals' different life chances and as an alternative to the heavy administrative burden of benefit systems.

Currently, UBI looks pretty unaffordable without very high levels of taxation, but I did wonder whether there is some adjustment to that which might play a role here. Currently, there are about 5 million people in this country who are members of public service pension schemes. They benefit, whether the schemes are funded or in large part unfunded, from an effective state guaranteed annuity within the schemes which is probably at the level of underpin of something just under $3 \%$ per annum real which is provided.

I do wonder whether a state-based solution could be made available to DC retirees, using part of their pension pot to buy a state guaranteed underpin. It may not consume the whole of their pension pot, but it could provide a bit of an underpin payable on top of state basic pension that would give them a bit of safety if they took a more speculative approach with the remainder of the pot.

What could be offered here could be immediate annuities. They could be guaranteed annuities for people who may be in poor health and were worried about legacy issues of the pot being consumed. It could provide for the deferred annuities where you bought at retirement age and did not kick in until age 80 or above at some level just in case you did manage to survive that long.

I think that will provide a level of basic benefit. As I say, it would also mean that the risk of these people falling back on state dependency if their money runs out would be lessened. I do think that there is scope here to consider a state backup, taking the population as a whole, to provide insurance that companies would struggle to provide.

I think that you have to look at it more holistically and not just in terms of "Gosh, we are giving away a very rich guarantee here". Are we costing it adequately? And think what the alternative would be in terms of benefit support that will be necessary.

Mr W.D.B. Anderson, F.I.A.: There is much to like in the paper, particularly the phased approach across retirement to thinking that annuities are much more appropriate later in life. The business case for 
justifying annuitisation becomes much stronger as people get older. That is because of the mortality dividend recycling benefit to which you have referred, and also because the upward pointing slope of futures on interest rates make later annuitisation much more appealing.

That is also why I think deferred annuities, unfortunately, are not particularly appealing at the moment - locking into low interest rates is probably not a great strategy.

If my own modelling and your modelling diverge at all, it is probably that I am more hawkish; my analysis is worse than yours. It probably reveals a worse downside than you are presenting in your numbers which, I suspect, is attributable to two things.

One is you have fitted your modelling to actual historical numbers and my forward-looking stochastic model of the future is probably worse than has been seen in the past. Secondly, I think that you are probably attributing too much emphasis to life expectancy, which is an average number of how long people might live, or a population level. Where you individualise the longevity, I think you see that, roughly speaking, there is a rule of thumb of about a one in 10 chance of people living $>10$ years longer than their life expectancy number.

If you were to ask people how long their pension would have to eke out to have a $90 \%$ confidence that they were not going to run out of money, you end up with a really unaffordably long period, which is again another reason why later life annuitisation becomes much more compelling.

Miss Morgan: The mass-market issue is one that does worry me quite significantly. Not only do we have savings rates in the UK that are way below where they should be, but once people reach retirement, they really do struggle to understand the different options that are available to them. This links into the fact that Scott and I suggested in the paper that there should not be just one default answer.

What we are really advocating is having a default framework, to help people in that particular situation. I think that probably could work in the mass-market, provided that the number of options that we have suggested in Figure 8 are relatively limited. What we talked about in the paper is possibly kite marking and a relatively limited number of options so people are not completely flummoxed by too much choice.

Mr Lothian: Regarding the point about the need for innovation, the fact that we do not have the tools in the market in the UK today, and in many places around the world, is exactly right. We need that innovation to bring those to the market.

Miss Morgan: We have talked a lot about deferred annuities, or lack of deferred annuities. The paper itself initially talks about something broader than just annuities. It talks about longevity protection as an idea.

In Australia, Mercers have launched some sort of longevity risk sharing idea for post-retirement, and it is those kinds of innovations that I see as being possible (for those who are 80-85 plus for protection) not just solutions that are provided from insurance companies.

The Chairman: What do you think about the role of the sponsor where you have DC plans? Do you really think companies will want to become involved in helping members post-retirement or will they 
be keen to just wash their hands of the members once they have reached retirement, given the various risks that are involved?

Miss Morgan: I think, in the UK, companies are more paternalistic than in a number of other countries. I often compare the UK to the US. In the US, fiduciaries and sponsors have been very keen to wash their hands of people once they reach retirement.

But, in more recent years, those plan sponsors have started to try to keep people in plan. We are starting to see a bit of a change in the US. The reason for this is because they want to keep their overall fee level down because fiduciaries in the US are being sued for picking investment answers that are too expensive. They see this as one of the ways to keep the expenses down by keeping people in plan in post-retirement. Historically, in the US, that risk of being sued by a pensioner in retirement was felt to be too great to keep people in plan. But now that is starting to change.

The other option to look at in the UK is obviously master trusts. Master trusts are in a very good position to be able to have something that rolls straight over into post-retirement for the mass-market.

Mr J. E. Gill, F.F.A.: I wonder if you want to comment about the political difficulties which you highlight. We appear to have a government which, rather than encouraging people to buy deferred annuities, wants to get them to sell their existing annuities; the exact opposite of your preferred hybrid solution.

I guess, in all of the discussions about this, there is an assumption about the concept of an income for life. There appears to be no political will whatsoever from any side for income for life. How are you going to solve the political problem?

Mr Lothian: It is one of the largest problems in pretty much all markets that I can think of round the world. There are movements in many markets. I think there is some lobbying going on in Australia to take pensions out of politics or politics out of pensions, whichever way round that might work. It would be a very bold move for any government to do it, especially when you have so many other challenges going on from the political sphere that are making politicians even more unpopular than they ever have been. It becomes a very difficult issue for them to put their short-term mandates on the line for such a long-term issue.

How can we get political will? I think that this is a huge problem. I do not think I have an answer here for you today, I am afraid.

Miss Morgan: Where we see success in some other countries is where not necessarily actuaries, but other lobbying bodies start to work to be able to get a better solution for the members rather than just the right solution for the politicians who are particularly concerned about keeping the economy going.

Mr Anderson: There seems to be repeated evidence from surveys that individuals underestimate how long they are likely to live. That then leads you to the question of how do you change public perceptions about how long people are likely to live. A great campaign, really, for the actuarial profession to take on.

I think that one of the issues that we have here is what psychologists call an information advantage, or an information bias, associated with people passing away. Think of the reaction to all the stars 
who passed away earlier this year with David Bowie, Terry Wogan, and Co. The news media came out with obituaries very quickly. There was a national mourning. There was no discussion on the news that day of all the people that did not die. It was a far more significant event, the story of all the people who did not die, but no discussion takes place about it.

Because the media works through personalisation of issues, you need to come up with role models to talk about people living a long time.

It would be great for insurance companies, for example, to search through all the records and identify all the annuitants who have gone on to live for many years, track them down and hear their life stories. Then use those stories to create an information campaign about people living a long time. That is just one thought of what you might do here. To me, you have to win back the information advantage into the favour of people and neutralise the bias that currently exists.

Mr R. W. Baird, F.F.A.: It may be sounding stupid, but one of the assumptions is one of stability of income. Is it true as you reach age 90 you need to have the same level income as when you retire at 65 ?

Miss Morgan: I think that point is well made. When you look at consumption it depends on country to country. The US is the most extreme in terms of consumption in the very later years because of the amount that is spent on medical in the last 10 years. But, typically, people spend more in the first 10 years, they spend less in the middle 10 years, and they spend significantly more in the last 10 years.

We have shown something that is obviously more simplistic than that because we did not spend a lot of time looking at consumption in this paper. Another step, beyond this paper, would be to look more closely into consumption in the UK, to be able to design products particularly around that aspect.

I think most people do not recognise that they have this U-shaped consumption path. Those of us who have done studies into it, see it.

The Chairman: That offers an opportunity perhaps for the Pensions Board to consider some research into consumption aspects.

Mr M. D. Paterson, F.F.A.: There is no mention of housing. It is very important, particularly in Britain, that a high percentage of this generation have housing. I think that is where their legacy for the future generation has come from.

The other thing is in terms of the U-shaped curve of consumption. I think there is very often a downsizing of housing somewhere along the line. I think that is an issue which has to be built into some of these thoughts.

Mr Lothian: I think it is true in many markets where there is a culture of home ownership that there is equity built up and there are products available in many markets which basically can reverse mortgage which allows an income to be taken from that particular asset. That is something we touch upon very briefly in the paper. It is another strategy that might be there for those markets.

Miss Morgan: Experience elsewhere around the world, though, is they are often not popular. While they theoretically make a lot of sense, they do not often have big take ups. 
The Chairman: May I invite Iain McLellan, from KPMG, to close the discussion? He is a senior actuary at KPMG's pension scheme based here in Scotland. He advises a wide range of corporate and trustee clients. He also has a degree in actuarial mathematics and statistics from Heriot-Watt and currently serves on the profession's Scottish Board.

Mr I. McLellan, F.F.A. (closing the discussion): Many of these issues have never been dealt with before in a DB world because we do not let people have any choice, or there is a very limited choice, between cash and an annuity at retirement.

I think further areas for research were highlighted such as reference to kite marking. As, probably with DC pre-retirement fund choices, the idea is to keep it as simple as possible and allow choices to be taken rather than lost in confusion over the variety of options.

Picking up one of the challenges about the implications of health and whether long-term care costs can be factored into products that have been designed, even in the UK, we have quite different challenges depending on where you happen to live at the moment.

Turning to comments from Harry Taylor, he highlighted the scope for innovation in the actuarial profession. Morris Paterson made comments regarding property and deferred annuities which may be purchased in terms of trying to bring additional wealth to the table. There are the effects of DC and the use of master trusts, which was referred to a number of times and certainly another area for further work.

John Hastings made some great comments about the challenges of post-retirement solutions: you still have to sell them pre-retirement. Again, there was the increased certainty which would help marketing and getting people engaged in terms of "Why would I save in the first place?" There were some interesting points about state sponsored solutions, particularly potentially at a low level (the post-retirement version of NEST (National Employement Savings Trust)).

As people will end up with small pots, could the government be in a position to attract annuitising, or in terms of a kick start to some sort of deferred annuity market?

Douglas had negative views about future investment returns, the challenge to individuals about their life expectancy, and the associated risks. You can talk to individuals about life expectancy, but they effectively wish it away: "My dad died at this age" or "My granny lived to 105". How we present the facts is part of any advice process (whether that is via an IFA (independent financial adviser) or any "Robo" advice). How we will bring that to life for an individual in a very simple way is always a massive challenge.

Russell Baird highlighted the analysis in the paper regarding the consumption in retirement, but giving individuals flexibility. The challenge is to allow them to decide at retirement how they want to see that coming through. But it is difficult for individuals at retirement to know what their requirements are, never mind that there is a U-shaped consumption curve.

I would say that through the comments, and through the paper, there is great coverage of the topic in general and areas for further investigation.

A couple of points which were not raised include, potentially, the use of funds for advice at retirement. While the idea of simplifying things, so that potentially for a mass-market audience the 
use of "Robo" advice can help to try to deal with the tension between people's needs and wants, because they cannot have it all, the challenge is at an individual level. No matter how "whizzy" your technology is, getting things set down to understand it and to use it is always a challenge. The advice gap is quite significant.

Also, there is the potential for the use of funds at retirement to pay for advice given at the time. Quite a big bill to pay, but given this will be probably the biggest financial decision you are making in your life, it is probably worthwhile doing, especially if it is going to be repeated advice to managing those individual accounts.

As for potential analysis or further review, such as looking at the non-insured element, for example individual accounts, and considering what are the successful strategies people adopt with those funds in terms of how theory deals with practice. If we are going to get into mass draw down, where do we see that, particularly from an IFA perspective in relying on advisers to help make the choices for how much people are annuitising and how much they are putting into individual accounts.

The Chairman: I would like to express my thanks and I am sure the thanks of all of us, to the authors, the opener, the closer and the various other contributors that we have had. 